Research Article

\title{
Study on the Rolling-Type Microvibration Isolation Mechanisms Based on Completely Elastic Contact
}

\author{
Gaofeng Guan $\left(\mathbb{D},{ }^{1}\right.$ Dengfeng Xu $\mathbb{D}^{2},{ }^{2}$ Yu Zhu, ${ }^{1,2}$ Qiang Yu $\left(\mathbb{D},{ }^{1}\right.$ and Qiang Li $\mathbb{D}^{3}$ \\ ${ }^{1}$ School of Mechatronics Engineering, University of Electronic Science and Technology of China, Chengdu 611731, China \\ ${ }^{2}$ Department of Mechanical Engineering, Tsinghua University, Beijing 100084, China \\ ${ }^{3}$ School of Information and Engineering, Wuchang University of Technology, Wuhan 430223, China \\ Correspondence should be addressed to Dengfeng Xu; xudf02@mails.tsinghua.edu.cn
}

Received 3 September 2018; Revised 14 January 2019; Accepted 3 February 2019; Published 25 February 2019

Academic Editor: Simone Cinquemani

Copyright (c) 2019 Gaofeng Guan et al. This is an open access article distributed under the Creative Commons Attribution License, which permits unrestricted use, distribution, and reproduction in any medium, provided the original work is properly cited.

The previous models of rolling-type mechanisms were built based on rigid contact and pure rolling motion, but when applied to ground microvibration isolation, a large error in the natural frequency was sometimes observed in the experiments. A new model of a common mechanism based on completely elastic contact is developed, and the expression of the natural frequency is provided under a microvibration condition. The experiments and analysis show that the proposed model is more accurate than the previous model, and the natural frequency is independent of the payload. The analysis shows that the proposed model is only suitable in the range of completely elastic contact, and the load range is provided after comparing the experimental results with existing theory.

\section{Introduction}

Many scholars have paid attention to rolling-type systems for seismic isolation during the past years, and many different rolling-type mechanisms have been proposed [1-7]. The previous models were all built based on rigid contact [8]. Natural frequency is one of the most important indexes used to evaluate the performance of an isolator. However, when these mechanisms are applied to microvibration isolation, huge error in the natural frequency is sometimes observed in the experiments, such as errors exceeding $100 \%, 250 \%$, and $100 \%$ in the previous studies $[5,6,9]$. Thus, some issues need to be reconsidered.

First, practical works occasionally display considerable differences. For example, in a seismic vibration, the amplitude and acceleration of a horizontal vibration can be more than $10 \mathrm{~cm}$ and $1 \times 10^{-1} \mathrm{~g}$, but for a ground microvibration, the two indexes can be less than $2 \mu \mathrm{m}$ and $1 \times 10^{-4} \mathrm{~g}$ [10-12]. Second, the practical state of motion is a rolling slide, instead of a pure rolling, based on the contact mechanics and creep theory of a wheel and rail system [13-15]. Many researchers have already discovered creepage and slide in seismic isolation experiments, namely, Dona et al. [16] and Matta et al. [17]. However, the previous models all neglected the slide behavior, and the effect of a slide on the natural frequency remains unknown. Third, Guerreiro et al. [18] found that rollingtype isolators are more suitable for light payload, but the boundary condition of light and heavy payloads was not provided. The previous models based on pure rolling motion and rigid contact did not consider the abovementioned problems. The present study, which is based on rolling-slide motion and elastoplastic contact, attempts to determine the reasons for the huge error in the natural frequency.

Figure 1 shows a general rolling-type mechanism of an elastic ball placed between two elastic bowls, which was proposed by Zhou et al. [2]. Symbols $m, r_{1}$, and $r_{2}$, represent the payload, ball radius, and radii of the upper and lower bowls, respectively.

The natural frequency of Zhou's model is expressed as $\sqrt{g /\left(2\left(r_{2}-r_{1}\right)\right)} /(2 \pi)$, which is only relevant to structural parameters that are independent of the load and material parameters; $g$ denotes the gravitational acceleration.

The rest of this paper is organized as follows. In Section 2 , the modeling process is presented. In Section 3, some 


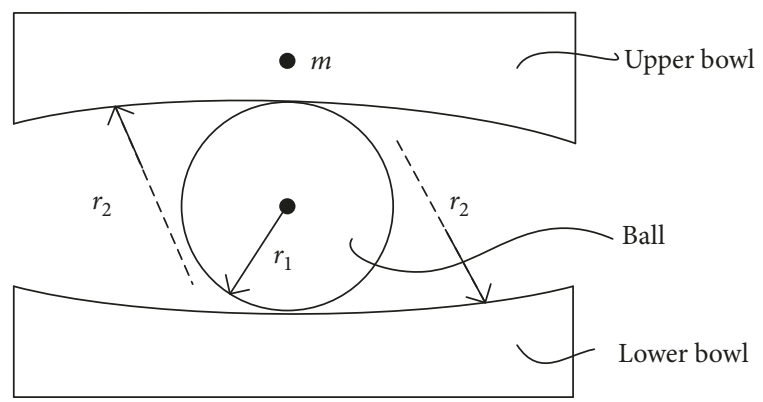

Figure 1: Elastic ball placed between two elastic bowls.

experiments and analysis that were conducted are provided. The conclusion is presented in Section 4.

\section{Modeling}

The schematic diagram of the general mechanism in the rolling-slide motion state is shown in Figure 2. Usually, rolling motion is accompanied by elastic deformation and creepage between the contact interfaces, and the actual state is called rolling-slide motion. Therefore, a difference exists between the center and circumferential displacements, as shown in Figure 2. The displacement in the spherical center is denoted as $L$, and the displacement in the spherical circumference is expressed as $L+\delta_{1}+\delta_{2}$. The elastic deformation and creep displacement are denoted as $\delta_{1}$ and $\delta_{2}$, respectively $[19,20]$.

The ratio between the displacement difference and center displacement is called the elastic creep rate. When two cylinders contact, the displacement can be expressed as follows $[19,20]$ :

$$
\xi=\frac{\delta_{1}+\delta_{2}}{L}=-\frac{\mu T}{2 r_{1} F_{\mathrm{n}}} .
$$

In equation (1), $\mu$ is the sliding-friction coefficient, which can be obtained by measurement experiments or by checking the mechanical design manuals, $r_{1}$ is the radius of the ball, $F_{\mathrm{n}}$ is the normal pressure, which can be approximately treated as the gravity of the payload, and $T$ is the rolling-resistance moment.

According to a similar method in the literature $[19,20]$, the elastic creep rate of the contact of two balls with each other can be obtained as

$$
\xi=\frac{\delta_{1}+\delta_{2}}{L}=\frac{3 \mu}{32 r_{1}}\left(\frac{6 r F_{\mathrm{n}}}{E}\right)^{1 / 3},
$$

where $E$ is the equivalent elastic modulus. $r$ and $E$ can be expressed as equations (3) and (4), respectively [15]:

$$
\begin{aligned}
& \frac{1}{r}=\frac{1}{r_{1}}-\frac{1}{r_{2}}, \\
& \frac{1}{E}=\frac{1-v_{1}^{2}}{E_{1}}+\frac{1-v_{2}^{2}}{E_{2}} .
\end{aligned}
$$

In equations (3) and (4), $v_{1}$ and $v_{2}$ are Poisson's ratios of the ball and upper and lower plates, respectively (here, we

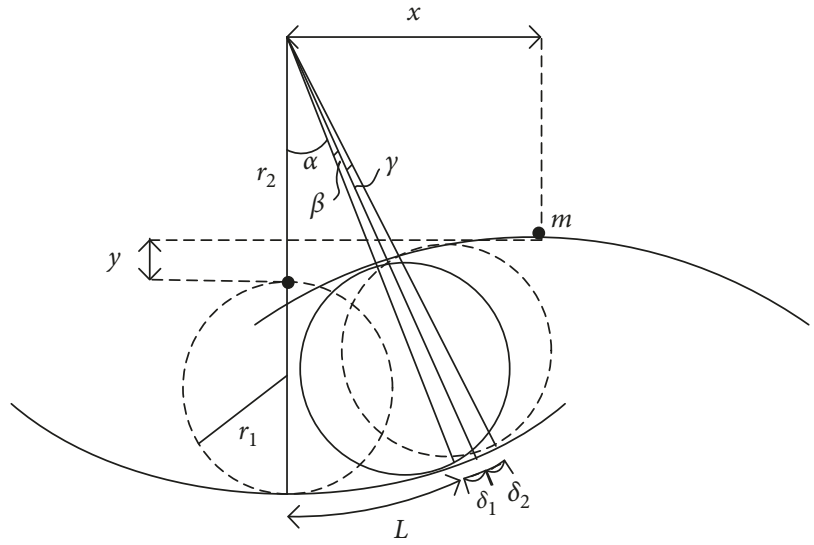

FIgURE 2: Schematic diagram of the rolling-slide motion.

assume that the upper and lower plates are made of the same material). $E_{1}$ and $E_{2}$ are the moduli of elasticity and the elastic modulus of the ball and upper and lower plates, respectively. $r_{1}$ and $r_{2}$ are the radii of the ball and the upper and lower plates, respectively.

In addition, we have the following relationship:

$$
\alpha: \beta: \gamma=L: \delta_{1}: \delta_{2} \text {. }
$$

The horizontal and vertical displacements of the system are expressed as

$$
\begin{aligned}
& x=2\left(r_{2}-r_{1}\right) \sin \alpha, \\
& y=2\left(r_{2}-r_{1}\right)(1-\cos \alpha) .
\end{aligned}
$$

The kinetic energy is expressed as

$$
T=\frac{1}{2} m\left(\dot{x}^{2}+\dot{y}^{2}\right)
$$

Because creep displacement $\delta_{2}$ does not store potential energy, the potential energy of the system consists of two parts, namely,

$$
V=V_{1}+V_{2}
$$

where $V_{1}$ is the gravitational potential energy and $V_{2}$ is the elastic potential energy due to the elastic deformation between the contact surfaces. Because $\delta$ is usually much smaller than $L, V_{1}$ can be approximately expressed as

$$
V_{1}=m g y \text {. }
$$

The elastic potential energy represents the sum of two contact surfaces of the upper and lower parts, which can be expressed as

$$
V_{2}=2 * \frac{1}{2} k_{\mathrm{t}} \delta_{1}^{2}
$$

In equation (10), tangential contact stiffness $k_{\mathrm{t}}$ is expressed as follows [15]:

$$
k_{\mathrm{t}}=\frac{8 G a}{(2-v)}
$$

In equation (11), $v$ denotes Poisson's ratio and $G$ denotes the equivalent shear modulus, which can be expressed as follows [15]: 


$$
G=\frac{E}{2(1+v)}
$$

In equation (11), $a$ denotes the radius of the contact area, which can be expressed as follows [15]:

$$
a=\left(\frac{3 r F_{\mathrm{n}}}{4 E}\right)^{1 / 3} \text {. }
$$

The kinetic equation of the conservative system can be obtained by the Lagrange equation:

$$
\frac{d}{d t}\left(\frac{\partial(T+V)}{\partial \alpha}\right)-\frac{\partial(T+V)}{\partial \alpha}=0 .
$$

After the introduction of various types of simplification, we can obtain

$$
2 m\left(r_{2}-r_{1}\right) \ddot{\alpha}+\left(m g+\left(r_{2}-r_{1}\right) k_{\mathrm{t}}\left(\frac{\delta_{1}}{L}\right)^{2}\right) \alpha=0 .
$$

The natural frequency of the system can be expressed as

$$
f=\frac{1}{2 \pi} \sqrt{\frac{m g+\left(r_{2}-r_{1}\right) k_{\mathrm{t}}\left(\delta_{1} / L\right)^{2}}{2 m\left(r_{2}-r_{1}\right)}} .
$$

According to Hertz contact theory, the round interfaces of the ball and bowls can be divided into a slide and an adhesive area, as shown in Figure 3. The ratio of the radii of the adhesive area to the contact area is expressed as follows [15]:

$$
\frac{c}{a}=\left(\frac{\mu F_{\mathrm{n}}-F_{x}}{\mu F_{\mathrm{n}}}\right)^{1 / 3}
$$

where $c$ and $a$ are the radii of the adhesive and contact areas, respectively, and $F_{x}$ denotes the tangential force.

Under a microvibration condition, horizontal-vibration acceleration $a_{1}$ is generally less than $1 \times 10^{-4} \mathrm{~g}$ [10]. $F_{x}$ has a maximum value of $m a_{1}$. The sliding-friction coefficient is between zero and one. $r_{1}$ is $0.0125 \mathrm{~m} . r_{2}$ is $0.32 \mathrm{~m} . E_{1}$ is $6.06 \times 10^{11} \mathrm{~Pa} . E_{2}$ is $6.06 \times 10^{11} \mathrm{~Pa}$. $v$ is 0.28 . The ratio of the adhesive and contact areas is shown in Figure 4.

Figure 4 shows that the ratio of the radii of the adhesive and contact areas is very close to one, which means that a slide area barely exists. Then, we have

$$
\delta_{2} \approx 0 \text {. }
$$

Therefore, equation (2) can be simplified as

$$
\xi \approx \frac{\delta_{1}}{L}
$$

Equation (18) shows that the difference in the center and circumferential displacements is induced by the elastic deformation of the adhesive area under a microvibration. Thus, the elastic creep rate can be approximately treated as the ratio of the elastic deformation and center displacement, as expressed in equation (19).

According to equation (19), equation (16) can be rewritten as

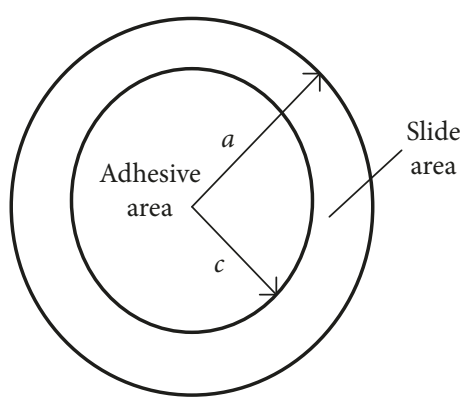

FIGURE 3: Division of the adhesive and slide areas in the contact surface.

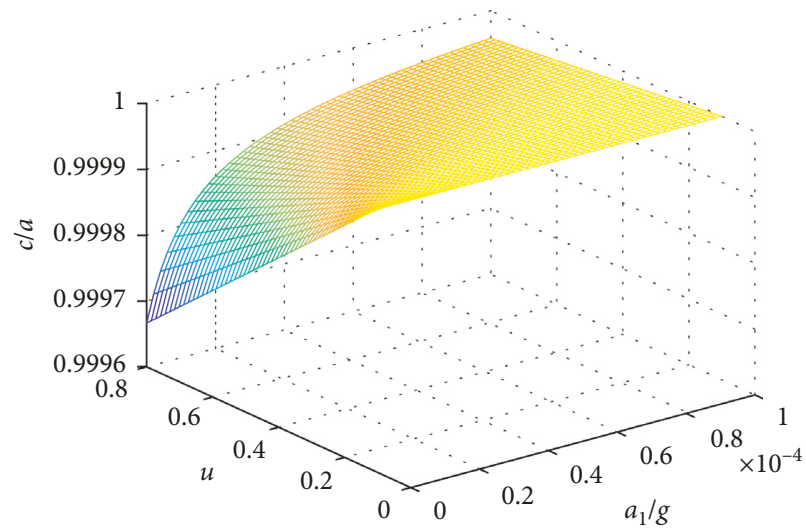

Figure 4: Ratio of the adhesive and contact areas.

$$
\begin{aligned}
f & =\frac{1}{2 \pi} \sqrt{\frac{m g+\left(r_{2}-r_{1}\right) k_{\mathrm{t}} \xi^{2}}{2 m\left(r_{2}-r_{1}\right)}} \\
& \approx \frac{1}{2 \pi} \sqrt{\frac{g}{2\left(r_{2}-r_{1}\right)}+\frac{27 g r_{2} \mu^{2}}{512 r_{1}\left(r_{2}-r_{1}\right)(2-v)(1+v)}} .
\end{aligned}
$$

Equation (20) indicates that the natural frequency in this study is larger than that in Zhou's model because the elastic potential energy stored in the contact interfaces increases the total potential energy.

\section{Experiments and Analysis}

The experimental device is shown in Figure 5. The isolator contains a top frame, a bottom frame, and three rolling-ball mechanisms. The top and bottom frames consist of the same two equilateral triangles with a side length of $0.2 \mathrm{~m}$ and thickness of $0.012 \mathrm{~m}$. Each rolling-ball mechanism is a sandwich structure in which a ball is placed between the upper and lower bowls, and the three rolling-ball mechanisms are evenly distributed at the three angles of the two equilateral triangles. The ground microvibration acts as the input signal, which is attenuated by the isolation system, and the load vibration acts as the output signal. The natural frequency is the core index, which is measured to evaluate the vibration isolation performance. 


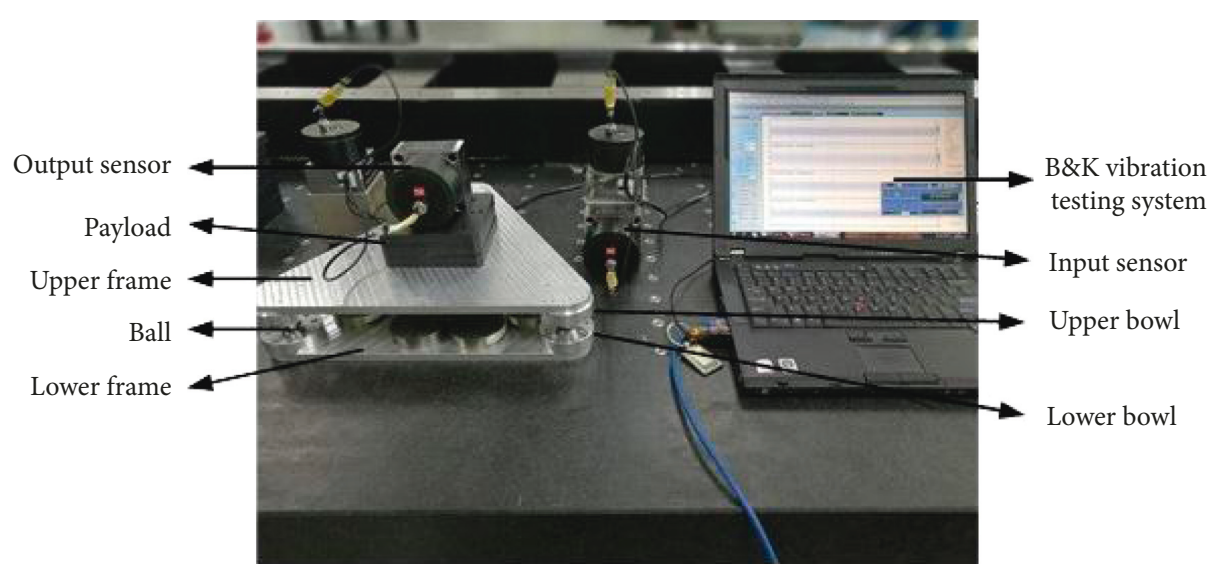

FIgURE 5: Photograph of the experimental device.
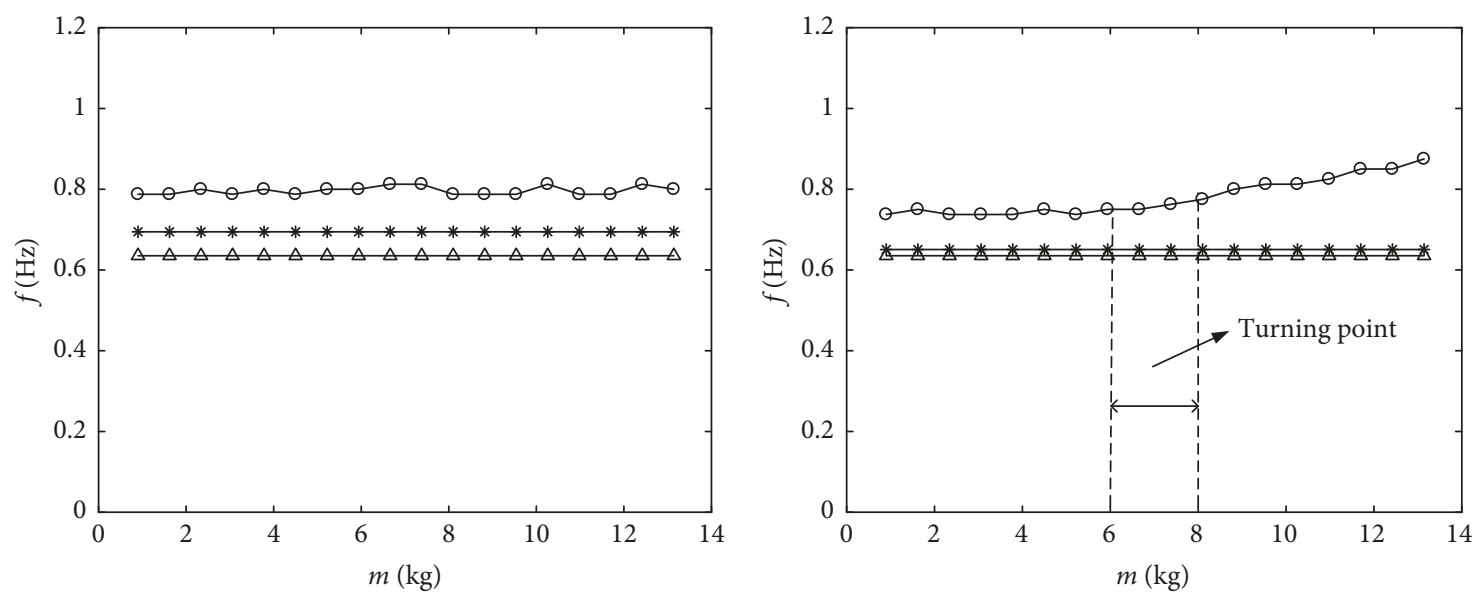

- - Measured data

- - Measured data

$\triangle$ Zhou's model

* Proposed model

$\triangle$ Zhou's model

* Proposed model

(a)

(b)
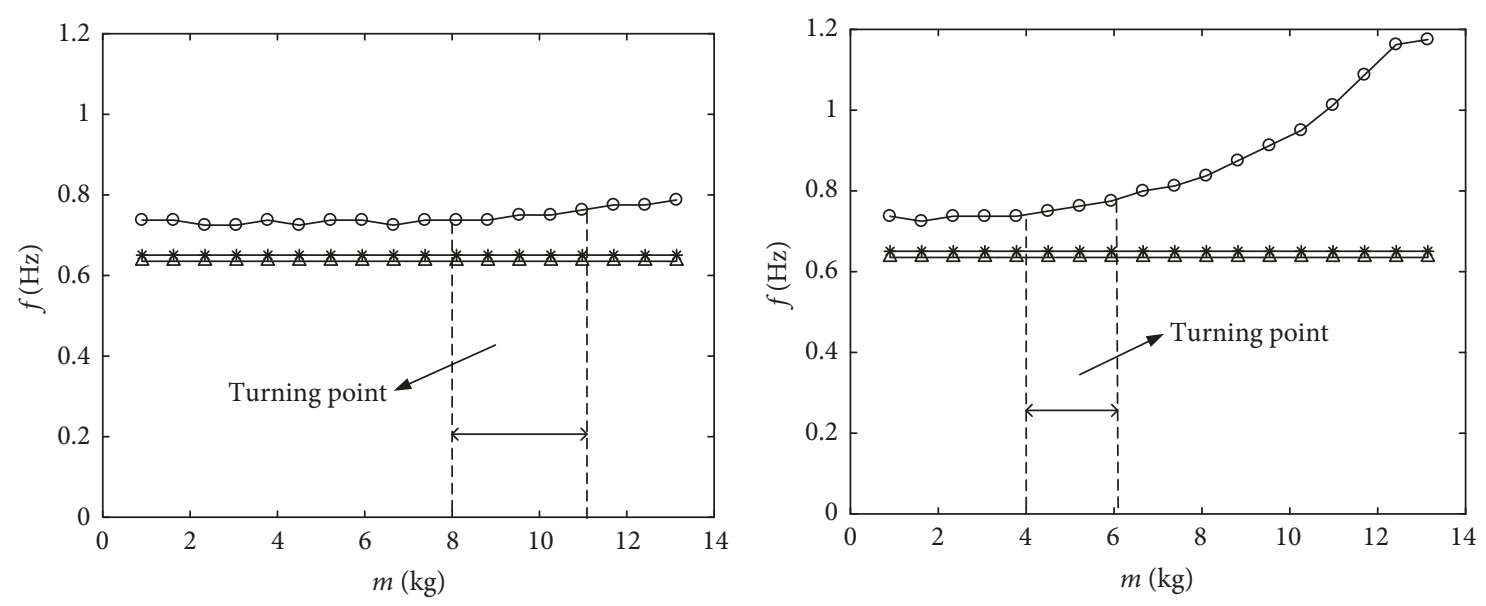

$\multimap$ Measured data
$\triangle \quad$ Zhou's model
$* \quad$ Proposed mode

- - Measured data

$\triangle$ Zhou's model

$\rightarrow$ Proposed model

(c)

(d)

Figure 6: Measured and theoretical results using different materials for the lower and upper bowls: (a) K20H hard alloy, (b) 45\# steel, (c) 6061 aluminum alloy, and (d) AZ91 magnesium aluminum alloy. 
To obtain a lower natural frequency, the structural parameters are selected as follows: $r_{1}$ is $0.0125 \mathrm{~m}$ and $r_{2}$ is $0.32 \mathrm{~m}$. The ball material is $\mathrm{K} 20 \mathrm{H}$ hard alloy. Four different materials are used in the lower and upper bowls, which are $\mathrm{K} 20 \mathrm{H}$ hard alloy, 45\# steel, 6061 aluminum alloy, and AZ91 magnesium aluminum alloy. Young's moduli of the abovementioned materials are $6.06 \times 10^{11}, 2.06 \times 10^{11}$, $7.20 \times 10^{10}$, and $4.50 \times 10^{10} \mathrm{MPa}$, respectively. The slidingfriction coefficients are approximately $0.4,0.2,0.2$, and 0.2 , respectively $[15,21]$. The initial payload per ball is $0.9 \mathrm{~kg}$ for the self-weight of the top frame and output sensor, and the load of the single ball is increased by $0.72 \mathrm{~kg}$ at each interval. The data are measured three times, and an average value is obtained. Figures 6(a)-6(d) show the results of the measured data and theoretical curves.

Figures 6(a)-6(d) show that the natural frequencies of Zhou's model and the proposed model are independent of the payload, and the proposed model is closer to the measured data compared with Zhou's model.

In addition, the measured data shown Figure 6(a) remain in the payload range from 0 to $13.14 \mathrm{~kg}$, whereas Figures 6(b)-6(d) show different characteristics in which the measured data show a gradual upward trend at some turning points. For the 45\# steel, 6061 aluminum alloy, and AZ91 magnesium aluminum alloy, the turning points are located in the ranges of $6-8 \mathrm{~kg}, 8-11 \mathrm{~kg}$, and $4-6 \mathrm{~kg}$, respectively.

What we notice is that the critical normal stress when the initial yield occurs exhibits the following trend [22]:

$$
\sigma=C_{v} \sigma_{\mathrm{y}}
$$

where $\sigma_{\mathrm{y}}$ is the yield strength of the material and $C_{v}$ is the coefficient determined by an fitting equation given by Jin and Chen [22]:

$$
C_{v}=0.5424 v^{2}+0.8796 v+1.3005 .
$$

By combining equations (21) and (22), the critical normal stresses of 45\# steel, 6061 aluminum alloy, and AZ91 magnesium aluminum alloy are 440, 720, and $256 \mathrm{MPa}$, respectively. The maximal normal stress is expressed as follows [15]:

$$
\sigma=\left(\frac{6 F_{\mathrm{n}} E^{2}}{\pi^{3} r^{2}}\right)^{1 / 3},
$$

where $F_{\mathrm{n}}$ is the normal pressure, which can be approximately treated as the gravity of the payload $m g$. By combining equations (21) and (23), the masses corresponding to the critical normal stress are $7.7,10.55$, and $4.66 \mathrm{~kg}$, respectively, which are approximately equal to the turning points of 7.38, 10.26 , and $4.51 \mathrm{~kg}$, respectively. For the $\mathrm{K} 20 \mathrm{H}$ hard alloy, the mass corresponding to the critical normal stress is $26.70 \mathrm{~kg}$; thus, a turning point is not shown in Figure 6(a).

The aforementioned analysis shows that the proposed model is only suitable in the range of completely elastic contact, which means that the following equation must be satisfied:

$$
0<m<\frac{\pi^{3} r^{2} C_{v}^{3} \sigma_{y}^{3}}{6 g E^{2}}
$$

If the payload exceeds the range, the bowls and the ball are elastoplastic contact. From Figure 6, we can see huge error will be observed in the range of elastoplastic contact. A future work of elastoplastic contact behavior of the mechanism will be carried out.

\section{Conclusion}

A general mechanism has been studied based on completely elastic contact, and some conclusions that are also suitable for other rolling-type mechanisms applied to microvibration isolation can be made as follows. First, in the region of completely elastic contact, the proposed model was more accurate than the previous model from the comparison of the measured data, and the model is only suitable in a given range. Second, in the region of elastoplastic contact, the natural frequency increased as the payload increased, and huge error will be observed.

\section{Data Availability}

The compressed file "Figures 6(a)-6(d)" used to support the findings of this study has been deposited in the Figsharerepository (https://figshare.com/s/02496f0b2ce4cc88b6ad). MATLAB Software can be used to open the ".m" and ".fig" type files, and Microsoft Excel Software can be used to open the ".xlsx" type files.

\section{Conflicts of Interest}

The authors declare that there are no conflicts of interest regarding the publication of this paper.

\section{Acknowledgments}

This work was supported in part by the National Science and Technology Major Project of China (2015ZX02104003) and in part by the Natural Science Foundation of Hubei Province of China (2018CFC889).

\section{References}

[1] T.-W. Lin and C.-C. Hone, "Base isolation by free rolling rods under basement," Earthquake Engineering \& Structural Dynamics, vol. 22, no. 3, pp. 261-273, 1993.

[2] Q. Zhou, X. Lu, Q. Wang, D. Feng, and Q. Yao, "Dynamic analysis on structures base-isolated by a ball system with restoring property," Earthquake Engineering \& Structural Dynamics, vol. 27, no. 8, pp. 773-791, 1998.

[3] R. S. Jangid and Y. B. Londhe, "Effectiveness of elliptical rolling rods for base isolation," Journal of Structural Engineering, vol. 124, no. 4, pp. 469-472, 1998.

[4] R. S. Jangid, "Stochastic seismic response of structures isolated by rolling rods," Engineering Structures, vol. 22, no. 8, pp. 937-946, 2000.

[5] Kemeny, "Micro vibration isolation device," US Patent 6517060B1, 2003.

[6] M. Yasuda, "Vibration control unit and vibration control body," US Patent 20030052247A1, 2003. 
[7] J. W. Butterworth, "Seismic response of a non-concentric rolling isolator system," Advances in Structural Engineering, vol. 9, no. 1, pp. 39-54, 2016.

[8] P. S. Harvey Jr. and K. C. Kelly, "A review of rolling-type seismic isolation: historical development and future directions," Engineering Structures, vol. 125, pp. 521-531, 2016.

[9] G. F. Guan, Q. Yu, and F. Shen, "Theory and experiments of a rolling-ball mechanism for horizontal vibration isolation," in Proceedings of Joint International Mechanical, Electronic and Information Technology Conference, pp. 846-852, Chongqing, China, December 2015.

[10] P. K. Subrahmanyan, A modal approach to precision motion control, Ph.D. thesis, Massachusetts Institute of Technology, Cambridge, MA, USA, 1999.

[11] M. Barghian and A. B. Shahabi, "A new approach to pendulum base isolation," Structural Control and Health Monitoring, vol. 14, no. 2, pp. 177-185, 2007.

[12] A. Rawat, N. Ummer, and V. Matsagar, "Performance of bidirectional elliptical rolling rods for base isolation of buildings under near-fault earthquakes," Advances in Structural Engineering, vol. 1, article 136943321772689, 2017.

[13] F. W. Carter, "On the action of a locomotive driving wheel," Proceedings of the Royal Society A: Mathematical, Physical and Engineering Sciences, vol. 112, no. 760, pp. 151-157, 1926.

[14] X. S. Jin, Study on creep theory of wheel and rail system and its experiment, Ph.D. thesis, Southwest Jiaotong University, Chengdu, China, 1999, in Chinese.

[15] V. L. Popov, Contact Mechanics and Friction: Physical Principles and Applications, Tsinghua University Press, Beijing, China, 2011, in Chinese.

[16] M. Dona, A. H. Muhr, G. Tecchio et al., "Isolation of light structures with rolling-ball rubber-layer system-characteristics and performance," in Proceedings of Second European Conference on Earthquake Engineering and Seismology, pp. 25-29, Istanbul, Turkey, August 2014.

[17] E. Matta, A. De Stefano, and B. F. Spencer Jr., "A new passive rolling-pendulum vibration absorber using a non-axialsymmetrical guide to achieve bidirectional tuning," Earthquake Engineering \& Structural Dynamics, vol. 38, no. 15, pp. 1729-1750, 2009.

[18] L. Guerreiro, J. Azevedo, and A. H. Muhr, "Seismic tests and numerical modeling of a rolling-ball isolation system," Journal of Earthquake Engineering, vol. 11, no. 1, pp. 49-66, 2007.

[19] Y. F. Xie and L. D. Wang, "Research on elastic creepages in rolling friction drive," Metrology Technology, vol. 5, pp. 3-4, 1990, in Chinese.

[20] J. J. Zhang and Y. Ma, "Elastical creepages between wheel and rail in double-disk involute measuring apparatus," Journal of Mechanical Transmission, vol. 31, no. 5, pp. 6-8, 2007, in Chinese.

[21] E. A. Arnold, K. A. Walter, A. Betzalel et al., ASM Handbook: Volume 18: Friction, Lubrication, and Wear Technology, The Materials Information Company, New York, NY, USA, 1992.

[22] H. P. Jin and J. G. Chen, "Calculation of critical parameters of elastic contact between rigid ball and plane," Journal of Mechanical Transmission, vol. 3, pp. 53-55, 2013, in Chinese. 


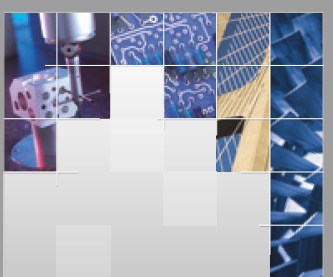

\section{Enfincering}
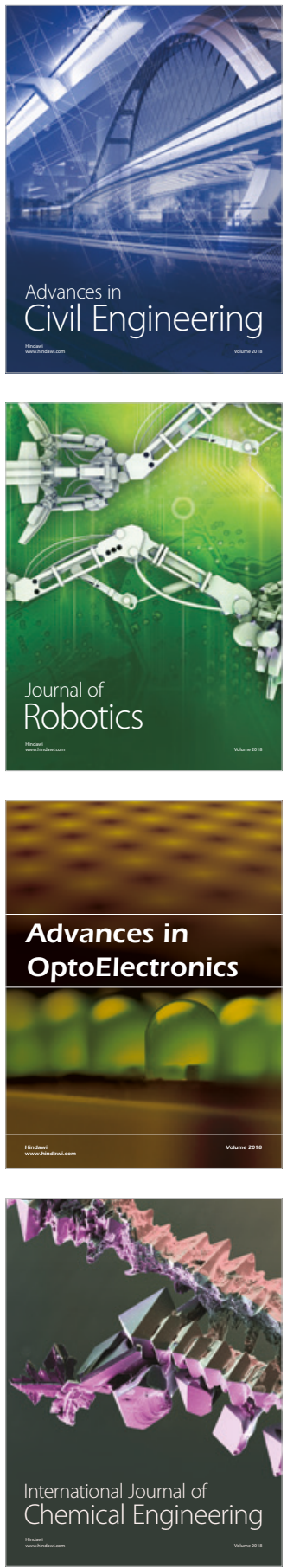

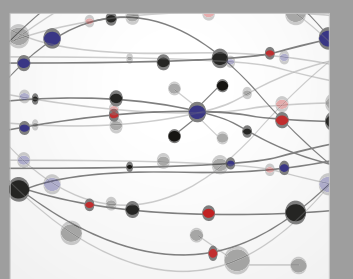

\section{Rotating \\ Machinery}

The Scientific World Journal

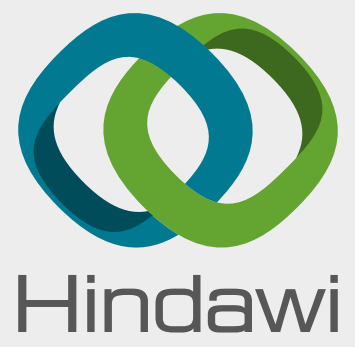

Submit your manuscripts at

www.hindawi.com
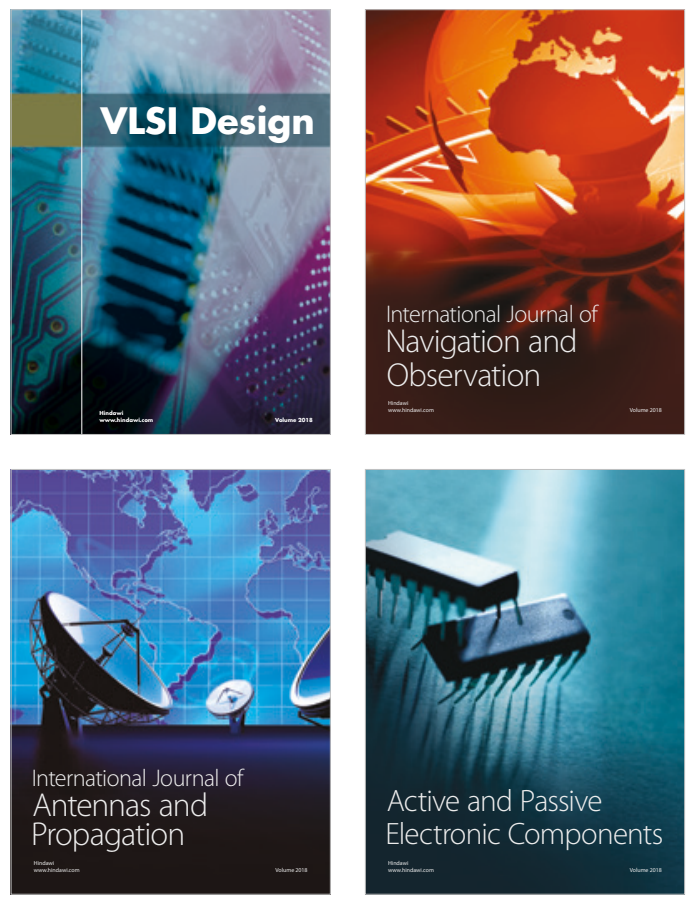
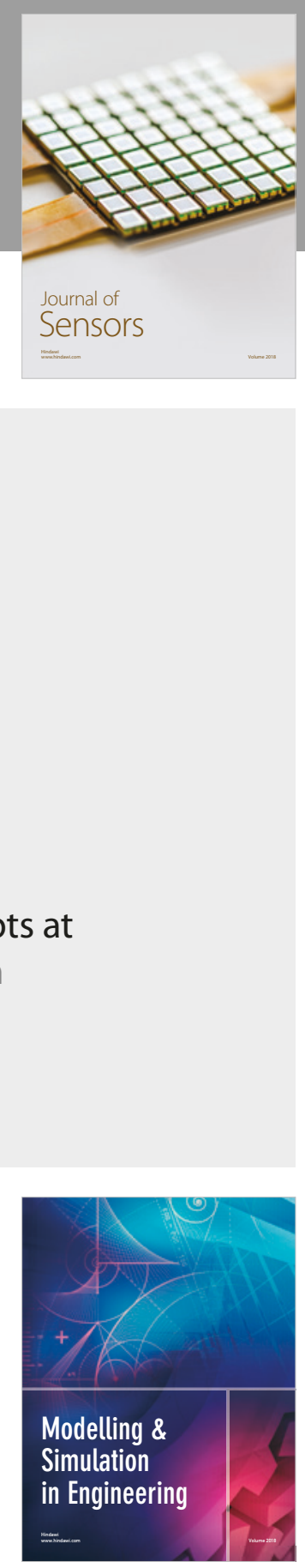

\section{Advances \\ Multimedia}
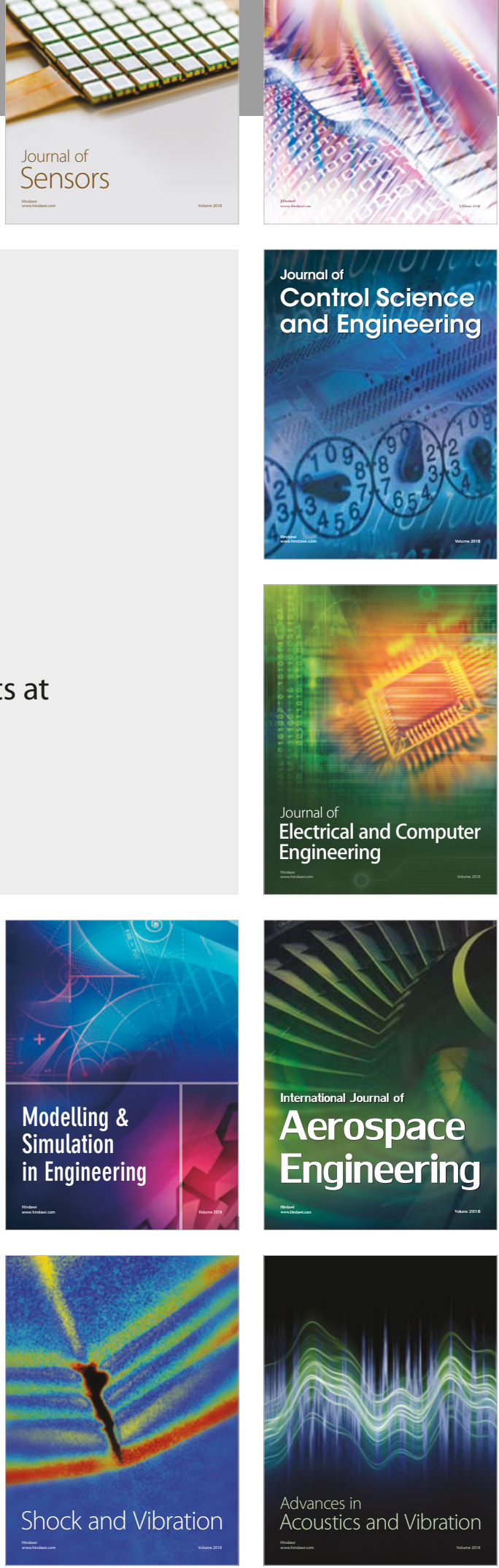